\title{
Lymphoepithelial carcinoma in the maxillary sinus: a case report
}

\author{
Darouichi Mohammed ${ }^{1}$, Alshammari Jaber ${ }^{2}$, Monnier Philippe ${ }^{2}$ and Sandu Kishore ${ }^{2,3^{*}}$
}

\begin{abstract}
Introduction: Lymphoepithelial carcinoma of the maxillary sinus is a very rare malignancy and it can be difficult to make a pre-operative diagnosis.

Case presentation: A 72-year-old Caucasian woman presented to our facility with an isolated right-side epistaxis that had been present for three months, with the results of a computed tomography scan showing a soft tissue mass in the right maxillary sinus with an impacted tooth. The results of a transnasal endoscopic biopsy were compatible with a lymphoepithelial carcinoma, following which our patient underwent a radical excision of the mass. The final histology results revealed lymphoepithelial carcinoma of the maxillary sinus with negative assays for Epstein-Barr virus. Our patient was given post-operative external radiotherapy and has remained disease-free at three-year follow-up.
\end{abstract}

Conclusions: This report details the diagnosis and management of a case of lymphoepithelial carcinoma of the maxillary sinus, which is a very rare malignant tumor with very little mention in the literature. Only a strong suspicion with systematic use of various patho-immunological tests helps to arrive at a definitive diagnosis by excluding other better-known tumors.

Keywords: Maxillary sinus, Lymphoepithelial carcinoma

\section{Introduction}

A majority of malignant tumors of the paranasal sinuses occur in the maxillary sinus [1,2]. Among malignant lesions of the maxillary sinus, lymphoepithelial carcinoma is very rare. Lymphoepithelial carcinoma is characterized by nests, sheets, or individual undifferentiated or poorly differentiated malignant epithelial cells surrounded and infiltrated by prominent components of small, mature lymphocytes and plasma cells [3]. The more frequent sites of these tumors are the nasopharynx, salivary glands and the larynx [4]. Very few cases of lymphoepithelial carcinoma arising in the maxillary sinus have been reported [5,6] with none precisely detailing its diagnostic characteristics and management. In this report we present a case of maxillary sinus lymphoepithelial carcinoma and review the radiological

\footnotetext{
* Correspondence: Kishore.Sandu@hopitalvs.ch

2Department of ORL and Head and Neck surgery, CHUV, Lausanne, Switzerland

${ }^{3}$ Department of ORL and Head and Neck surgery, L'Hôpital du Valais, Center Hospitalier du Center du Valais-CHCV, 1950, Sion, Switzerland

Full list of author information is available at the end of the article
}

findings, macroscopic and microscopic features, immunohistology and the treatment options available.

\section{Case presentation}

A 72-year-old Caucasian woman presented to our facility with an isolated right-side epistaxis that had been present for three months without other associated otolaryngological, ophthalmological or neurological symptoms. There was no history of trauma or chronic sinonasal infections. Ten years prior to the incident, our patient was diagnosed as having breast cancer and was treated with surgery and chemoradiotherapy. The results of a physical examination were normal except for a thread of blood coming out of the right middle meatus. A neck examination revealed no palpable lymph nodes. Routine laboratory investigation results were normal. A paranasal sinus (PNS) computed tomography (CT) scan showed expansion of the right maxillary sinus by a homogenous soft tissue mass without calcification, occupying the entire sinus cavity. The sinus walls were intact with no bony erosion. There was an impacted tooth visible inside the mass (Figure 1). Other sinus cavities were

\section{() BioMed Central}

(c) 2012 Mohammed et al.; licensee BioMed Central Ltd. This is an Open Access article distributed under the terms of the Creative Commons Attribution License (http://creativecommons.org/licenses/by/2.0), which permits unrestricted use distribution, and reproduction in any medium, provided the original work is properly cited. 


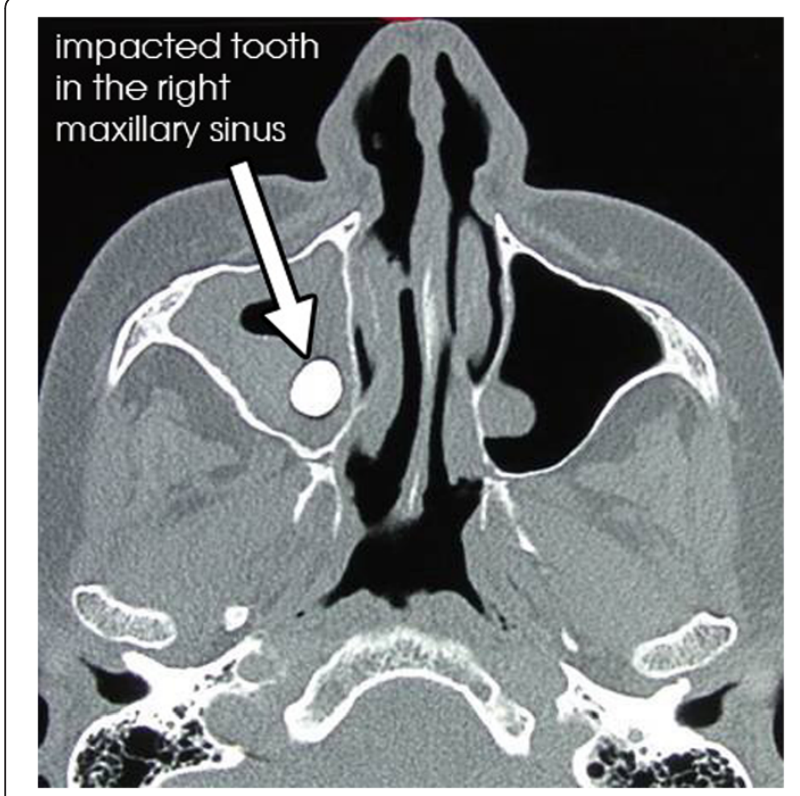

Figure 1 Axial computed tomography image showing a homogenous soft tissue mass occupying the entire right maxillary sinus with an impacted tooth.

normal. Endoscopic maxillary sinus meatotomy with tissue biopsy revealed carcinoma of the lymphoepithelial type. Our patient underwent a lateral rhinotomy with an orbital floor and hard palate saving maxillectomy, with complete excision of the tumor.

Histopathological examination (Figure 2) revealed a poorly differentiated carcinoma composed of malignant epithelial cells having large oval vesicular nuclei and containing fine chromatin with prominent one to three eosinophilic nucleoli. The tumor showed large quantities

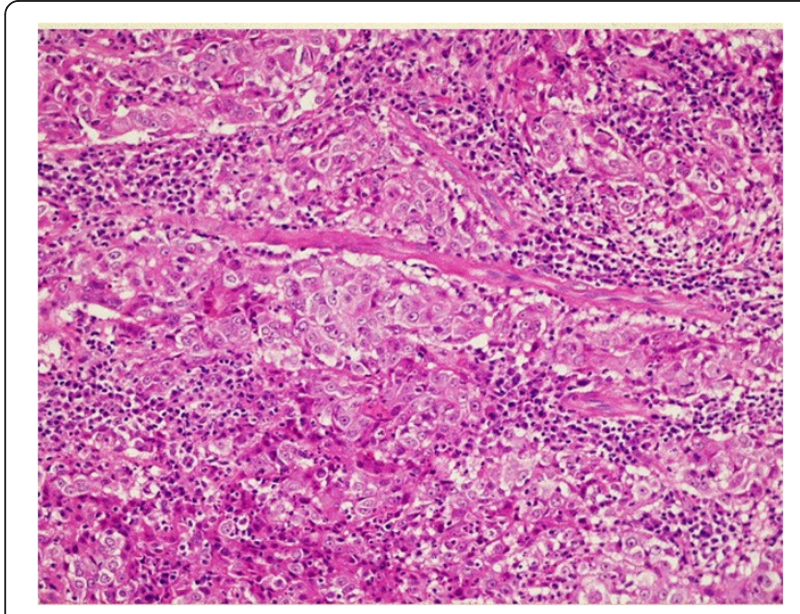

Figure 2 Histological slide showing malignant epithelial cells with large oval vesicular nuclei containing fine chromatin, prominent eosinophilic nucleoli and large quantities of lymphocytes and plasma cells. of lymphocytes and plasma cells. Immunohistochemical staining revealed that these cells were positive for pancytokeratin marker (MNF 116), proving the epithelial nature of these cells. Tests for cytokeratin (CK) 5/6 were mildly positive and favored squamous differentiation, while CK7 and carcinoembryonic antigen (CEA) tests were negative. By performing these investigations, we excluded a poorly differentiated squamous carcinoma. Melanin marker studies excluded a malignant melanoma. A CK20 antigen test result was negative, thus excluding an intestinal type of adenocarcinoma. There was a strong positivity for the proliferative marker Ki-67 (MIB-1) (Figure 3). Results of hybridization assays for Epstein-Barr virus were negative. Thus, the immunohistochemical studies were diagnostic for a lymphoepithelial carcinoma. External radiotherapy with a cumulative dose of 48Gy was delivered post-operatively. Our patient showed satisfactory treatment response and has been followed up very closely over the last three years. She has remained free of disease with no locoregional or distant metastasis.

\section{Discussion}

Lymphoepithelial carcinoma of the maxillary sinus is a very rare malignant tumor and was described for the first time by Schminke and Regaud in 1921 [7]. The lymphoepithelial carcinoma frequently develops in the nasopharynx, salivary glands and the larynx. More rarely, it affects the lungs, esophagus, stomach, pancreas, skin, cervix, endometrium, vulva, kidney, bladder, and central nervous system [8]. In the majority of cases, patients are asymptomatic, and the lesion is discovered incidentally by imaging [9]. Otherwise, patients complain of nonspecific sinonasal symptoms or may have obstructive nasal symptoms related to acute or chronic maxillary sinusitis [6] and rarely present with epistaxis, as in our

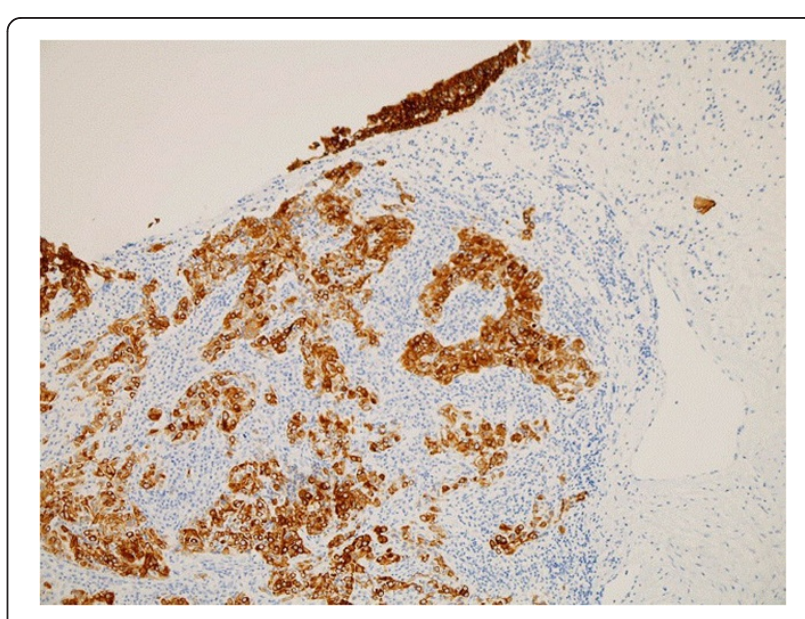

Figure 3 Histological slide showing malignant epithelial cells with a strong positivity for proliferative marker Ki-67 (MIB-1). 
patient. There is a strong association with an Epstein-Barr virus (EBV) infection [10]. Interestingly, patients with lymphoepithelial carcinoma in Western Europe and the USA are usually Epstein-Barr virus negative [11]. According to Lezzoni et al. the presence or absence of Epstein-Barr virus in the lymphoepithelial carcinoma of the maxillary sinus does not have any prognostic importance [12].

The lymphoepithelial carcinoma developing from the maxillary sinus can present as an aggressive tumor with signs of local invasion to nerves, orbit, or the rhinopharynx [13]. In general, the routine laboratory tests are normal. In terms of imaging, the lymphoepithelial carcinoma of the maxillary sinus appears as a diffuse opacity of soft tissue density on standard radiography [14]. Paranasal sinus CT scan highlights a solid homogenous mass occupying the maxillary sinus cavity that is not enhanced with an intravenous contrast injection [15]. In our patient's case, she had an impacted tooth inside the mass. There are no pathognomic radiological criteria that differentiate the lymphoepithelial carcinoma from other tumors of the maxillary sinus, especially squamous cell carcinomas or lymphomas. All these three tumors are locally destructive and have metastases to retropharyngeal and cervical nodes $[11,15]$. In general, clinicoradiological tests are noncontributory to the final diagnosis. Histology and immunohistochemical analysis establish the definitive diagnosis of a lymphoepithelial carcinoma. The microscopic features of this tumor show epithelial cells with eosinophilic cytoplasm. Their large oval nuclei have fine vesicular chromatin with one to three prominent red nucleoli. The fibrous stroma is heavily infiltrated by plasma cells and lymphocytes. Immunohistochemical staining shows that epithelial cells of lymphoepithelial carcinoma stain positively for pancytokeratin marker (MNF 116) and MIB-1 and stain negatively for CK 5/6, CK 7, and CEA. There is no immune reactivity for melanin A marker and CK 20.

Because of the limited number of cases, there is no standardized treatment policy reported to date for lymphoepithelial carcinoma of the maxillary sinus [3]. The initial treatment for maxillary sinus tumors has always been surgery. Lymphoepithelial carcinoma is known to be radiosensitive and hence we decided on a course of postoperative radiotherapy for our patient [14]. Adjuvant chemotherapy and neck management has been suggested for advanced and extensive disease [3]. Our patient did not receive any chemotherapy and neck management as she did not have neck metastasis. The rate of recurrence in maxillary sinus lymphoepithelial carcinoma is reported to be roughly 25 percent [15]. A regular follow-up with periodic CT scans is recommended.

\section{Conclusions}

Lymphoepithelial carcinoma of the maxillary sinus is a very rare malignant tumor with little mention in the literature. Its pre-operative diagnosis is difficult and the final definitive diagnosis is established by histopathological examination and immunohistochemical studies. The treatment consists of surgery and radiotherapy with the possibility of achieving acceptable cure rates. A strong suspicion and systematic use of various immunological tests helps to arrive at a definitive diagnosis by excluding other better-known tumors.

\section{Consent}

Written informed consent was obtained from the patient for publication of this case report and any accompanying images. A copy of the written consent is available for review with the Editor-in-Chief of this journal.

\section{Competing interests}

The authors declare that they have no competing interests in the preparation of this article.

\section{Authors' contributions}

DM, collection of data, manuscript preparation; AJ, collection of data, manuscript preparation; MP, manuscript preparation, analysis; SK, manuscript preparation, analysis. SK was the major contributor to writing the manuscript. All authors read and approved the final manuscript.

\section{Acknowledgements}

We thank Ms. Aida and Mr. Oussama Darouichi for their help in the preparation of this article.

\section{Author details}

'Department of Radiology, Hôpital Neuchatelois, La Chaux-de-Fonds, Switzerland. 'Department of ORL and Head and Neck surgery, CHUV, Lausanne, Switzerland. ${ }^{3}$ Department of ORL and Head and Neck surgery, L'Hôpital du Valais, Center Hospitalier du Center du Valais-CHCV, 1950, Sion, Switzerland.

Received: 19 July 2012 Accepted: 10 October 2012

Published: 11 December 2012

\section{References}

1. Blanco Al, Chao KS, Ozyigit G, Adli M, Thorstad WL, Simpson JR, Spector GJ, Haughey B, Perez CA: Carcinoma of paranasal sinus: long-term outcomes with radiotherapy. Int J Radiat Oncol Biol Phys 2004, 59:51-58

2. Dulguerov P, Jacobsen MS, Allal AS, Lehmann W, Calcaterra T: Nasal and paranasal sinus carcinoma: are we making progress? A series of 220 patients and a systematic review. Cancer 2001, 92:3012-3029.

3. Hyun J, Seong Kook P, Kyung Wook H, Mi Seon K: Lymphoepithelial carcinoma of the maxillary sinus with orbital invasion. Auris Nasus Larynx 2009, 36:487-490.

4. Coskun BU, Cinar U, Sener BM, Dadas B: Lymphoepithelial carcinoma of the larynx. Auris Nasus Larynx 2005, 32:189-193.

5. Zong Y, Liu K, Zhong B, Chen G, Wu W: Epstein-Barr virus infection of sinonsal lymphoepithelial carcinoma in Guangzhou. Chin Med J (Engl) 2001, 114:132-136

6. Dubey P, Ha CS, Ang KK, El-Naggar AK, Knapp C, Byers RM, Morrison WH: Nonnasopharyngeal lymphoepithelioma of the head and neck. Cancer 1998, 82(8):1556-1562.

7. Ejaz A, Wenig BM: Sinonasal undifferentiated carcinoma: clinical and pathological features and a discussion on classification, cellular differentiation, and differential diagnosis. Adv Anat Pathol 2005, 12(3):134-143

8. Ewing J: Lymphoepithelioma. Am J Pathol 1929, 5:99-107.

9. Sone M, Nakahima T, Nagasaka T, Itoh A, Yanagita N: Lymphoepitheliomalike carcinoma of the larynx associated with an Epstein-Barr viral infection. Otolaryngol Head Neck Surg 1998, 119:134-137. 
10. Franchi A, Moroni M, Massi D, Paglierani M, Santucci M: Sinonasal undifferentiated carcinoma, nasopharyngeal-type undifferentiated carcinoma, and keratinizing and non-keratinizing squamous cell carcinoma express different keratin pattern. Am J Surg Pathol 2002, 26:1597-1604

11. Sckolnick J, Murphy J, Hunt JL: Microsatellite instability in nasopharyngeal and lymphoepithelial carcinomas of the head and neck. Am J Surg Pathol 2006, 30:1250-1253

12. lezzoni JC, Gaffey MJ, Weiss LM: The role of Epstein-Barr virus in lymphoepithelioma-like carcinomas. AmJ ClinPathol 1995, 103:308-315.

13. Qureshi SS, Chaukar DA, Talole SD, Dcruz AK: Clinical characteristics and outcome of non-squamous cell malignancies of the maxillary sinus. J Surg Oncol 2006, 93:362-367.

14. Mosesson RE, Som PM: The radiographic evaluation of sinonasal tumors: an overview. Otolaryngol Clin North Am 1995, 28:1097-1115.

15. Parsons JT, Kimsey FC, Mendenhall WM, Million RR, Cassisi NJ, Stringer SP: Radiation therapy for sinus malignancies. Otolaryngol Clin North Am 1995, 28:1259-1268.

doi:10.1186/1752-1947-6-416

Cite this article as: Mohammed et al:: Lymphoepithelial carcinoma in the maxillary sinus: a case report. Journal of Medical Case Reports 2012 6:416.

\section{Submit your next manuscript to BioMed Central and take full advantage of:}

- Convenient online submission

- Thorough peer review

- No space constraints or color figure charges

- Immediate publication on acceptance

- Inclusion in PubMed, CAS, Scopus and Google Scholar

- Research which is freely available for redistribution 